\title{
Real Estate Brokers and Commission: Theory and Calibrations
}

\author{
Oz Shy
}

\begin{abstract}
:
The author constructs a theoretical model to examine the effects of an inherent conflict of interest between a seller of a house and the real estate broker hired by the seller. The model is then used to calibrate the broker's commission rates that would maximize the seller's expected gain. The findings suggest that while the pressure brokers exert on sellers to reduce prices generates faster sales and hence improves social welfare, the usual commission rate of 6 percent exceeds the seller's value-maximizing rate if the sale is handled by a single agent. On the other hand, if several agents (such as the buyer's and seller's brokers and the agencies that employ these realtors) split the commission, then a 6 percent commission rate may be required to motivate the broker to sell at a high price.
\end{abstract}

Keywords: real estate brokers, selling a house, conflict of interest, middleman, commission, price fixing

\section{JEL Classifications: L85}

Oz Shy is an economist in the research department of the Federal Reserve Bank of Boston. His e-mail address is oz.shy@bos.frb.org.

This paper, which may be revised, is available on the web site of the Federal Reserve Bank of Boston at http://www.bos.frb.org/economic/wp/index.htm.

I thank Mary Burke for most valuable comments and suggestions on an earlier draft.

The views and opinions expressed in this paper are those of the author and do not necessarily represent the views of the Federal Reserve Bank of Boston or the Federal Reserve System.

This version: September 3, 2009 


\section{Introduction}

There may be several reasons why sellers of private homes hire real estate brokers to handle the sale of their houses.

Two-sided market and network effects: Real estate brokers are connected via computerized networks that expose them to a large variety of houses for sale. Buyers are aware of that and will therefore hire an agent who is also connected to the same network. Sellers know that buyers tend to hire agents who are also on this network, which induces more sellers to enlist. This "snowball" effect can potentially magnify until all sellers and buyers connect via agents to the same network of realtors.

Nonresident sellers: Sellers who don't live in their own houses may gain additional benefits from having an agent working on the sale of their houses.

Other benefits: Even if the seller resides in the house, the seller may want an agent to screen potential buyers and to provide more "expert" information on the housing situation in a particular area.

Confidence: Selling and buying a house constitutes the major transaction of households. Some people can find "comfort" in having a real estate broker "holding their hand" while also offering a second opinion before final decisions are made.

Despite the above-listed benefits to sellers, there are also two major drawbacks from employing a real estate broker.

Commission: Sellers in the United States pay 6 percent of the final price to their real estate agent.

Conflicting interests: Agents may provide sellers with certain information on the housing market in order to lead them to settle on a lower price compared with the price that would maximize sellers' expected gain. Lower prices would increase the probability of finding a buyer and would also shorten brokers' expected waiting time until the transaction takes place, allowing them to collect their commission sooner. 
The first goal of this paper is to construct a simple analytical model that investigates realtors' incentives to lower the price of the house in order to secure the sale of a house. This happens because brokers' commission constitutes only a small fraction of the transaction value, thus, brokers often have an incentive to "convince" sellers that waiting for a higher-paying buyer would be risky. Lower prices increase the probability of a sale and hence yield a faster sale. Faster sales often reduce brokers' costs by more than the extra commission they might receive from trying to sell at higher prices.

The second goal of this paper is to calibrate the brokers' commission rate that maximizes sellers' net-of-commission gains from selling their houses. The calibrated rates may provide a rough estimate of whether the widely used uniform 6 percent commission rate reflects collusion among real estate agencies (in which case, the calibrated values should be much lower than the observed value of 6 percent), or whether this rate is competitively determined (in which case the calibrated values should be around the observed value of 6 percent). This investigation is important in view of the long-term investigations held by the Federal Trade Commission (FTC) and the Department of Justice (DOJ) concerning the possibility that the widespread use of the 6 percent commission rate may reflect collusive behavior in the real estate brokerage industry.

Most sellers in the United States pay 6 percent commission to real estate brokers. However, under some circumstances, an individual agent may receive only around 1.5 percent out of the total commission because the seller's and the buyer's agents (if they are not the same) tend to split the 6 percent commission. Then, each agency may take half of the remaining 3 percent, leaving the individual agent, who exerts most of the effort, with only 1.5 percent. Outside the United States, sellers' commission rates are generally much lower, often ranging from 1.5 percent to 2 percent. This may be a consequence of the fact that buyers also pay some commission to brokers. Clearly, it is a puzzle why discount real estate brokers are not observed more frequently in the United States, offering perhaps more limited services at a discount. Discount brokers are now widely observed in financial markets. Indeed, antitrust authorities have expressed many concerns that the uniform 6 percent commission rate may reflect collusive behavior, see FTC \& DOJ (2007). 
In order to conduct the above two investigations, the paper develops a dynamic model in which a seller of a house hires a real estate broker to handle the sale of the house. Both the seller and the broker bear costs of delay each time the broker fails to sell the house and the sale continues in a subsequent period. It is shown that the broker would recommend a lower price than the price that maximizes the seller's expected gain as long as the broker's commission rate is below 50 percent, which is always the case. In other words, sellers prefer setting a higher price, which generally prolongs the sale of the house, compared with the price that would be set by a commission-paid real estate broker.

The paper first investigates a market in which the price of the house is determined by the seller while the brokers' commission is exogenously determined, say by the association of real estate brokers. The second investigation computes the commission rate that maximizes the expected gain of a house seller assuming that the price of the house is determined by the real estate broker and not by the seller. ${ }^{1}$ This assumption generates an incentive on the part of sellers to pay some commission to brokers in order to motivate brokers to avoid setting a low price just to accelerate the sale of the house in order to minimize the broker's cost of delay. This model is then used to calibrate the sellers' most-desired commission rate, using data on housing prices and costs of delay. The calibration results hint that the ongoing 6 percent commission rate, if paid to a single broker, far exceeds the commission rate that would be preferred by a seller, despite the fact that a higher commission rate would motivate the broker to ask for a higher price. This, however, need not be the case if the commission is split among several brokers and agencies. The concluding section provide a further discussion of this issue.

The idea that house sellers and real estate brokers have conflicting interests is not new. In fact, Levitt and Dubner (2005) and Levitt and Syverson (2005) test the hypothesis that real estate brokers sell their clients' homes at lower prices than the prices they charge for selling their own homes. They find that homes owned by real estate agents sell for about 3.7 percent higher

\footnotetext{
${ }^{1}$ Clearly, the seller has the final say on the price. However, in many cases, real estate brokers have a great deal of influence on sellers' pricing decisions, basically by providing certain information on the market thereby leading the seller to believe that the price must be lowered. In this case, the assumption that brokers set the price is not that far from reality. Brokers often exert pressure on buyers to lower their price by telling sellers that they will not be able find buyers at the price they want.
} 
than other houses and stay on the market about 9.5 days longer. These results support the main result that real estate brokers tend to exert pressure on sellers to price below the levels that maximize sellers' expected gains.

The literature on middlemen has focused mainly on some aspects of incomplete markets and incomplete information. Garella (1989) and Biglaiser (1993) investigate the role played by middlemen in markets characterized by "lemon problems" and adverse selection. Biglaiser and Friedman (1994) model the role of a middleman as alleviating producers' moral hazard problem by reducing the sales of products that are found to be of a lower quality than what producers claim them to be. Hackett $(1992,1993)$ compares the incentives to invest in sales promotion between two types of agents: a dealer and a consignment contracted agent. Hackett (1992) demonstrates that an increase in demand variance increases the relative profitability of agent intermediary contracts. Rubinstein and Wolinsky (1987) and Yavaș (1994) describe the role of middlemen as shortening the time it takes to match sellers with buyers in bilateral search markets. Zorn and Larsen (1986), Schroeter (1987), Knoll (1988), and Carroll (1989) analyze the relative efficiency of a fixed-percentage commission over a fixed fee. The basic idea is that brokers exert more effort on high-priced houses under a percentage commission arrangement than under a fixed fee contract.

The present paper differs from the above literature in that it does not attempt to explain the role played by middlemen. Instead, it has a much narrower scope, which is to measure the magnitude of the conflict of interest between sellers and their realtors by examining the difference between house prices set by sellers and their realtors. ${ }^{2}$

Finally, some researchers have examined homeowners' choices of price and whether and when to employ a realtor. Salant (1991) computes the optimal time for a seller to switch from selling a house by owner to selling via a broker. More recently, Merlo, Ortalo-magné, and Rust (2008) provide theoretical and empirical investigations why homeowners are reluctant for a long period of time to reduce the price of the houses they sell.

\footnotetext{
${ }^{2}$ It should be mentioned that Rubinstein and Wolinksy (1987) as well as Hackett (1992, 1993) have also recognized that the way that middlemen contract with trading partners affects the distribution of gains from trade between sellers and buyers.
} 
The paper is organized as follows. Section 2 demonstrates the inherent conflict between a seller and a real estate broker using a simple example with two types of buyers who differ in their willingness to pay for a house. Section 3 extends the model to a continuum of buyer types. Section 4 constructs a model in which the broker's commission is determined by a seller who maximizes the expected net-of-commission gain from selling a house. Using this model, Section 5 calibrates the seller-determined commission rate for a wide variety of costs of delay that are borne by sellers and brokers, and for various distributions of buyers' willingness to pay for a house. Section 6 concludes with several discussions of further investigations and some unresolved issues.

\section{Seller-determined Price with Exogenously Given Com- mission Rate: Two Buyer Types}

This section constructs a simple non-calculus example to illustrate the conflict of interest between a seller of a house and a real estate agent/broker. In this model, the broker's commission is exogenously given, whereas the price of the house is determined by the seller. ${ }^{3}$ Section 4 analyzes an alternative market structure in which the broker's commission is determined by the seller, whereas the price of the house is determined (or heavily influenced) by the broker. Suppose there is a large number of potential buyers. A fraction $\beta$ of these buyers have a high valuation for the house, denoted by $b_{H}$. A fraction $1-\beta$ are low-valuation buyers with a maximum willingness to pay of $b_{L}$, where $b_{H}>b_{L}>0$.

The seller sets the price $p$. Because there are only two types of buyers, the seller should either set a low price $p=b_{L}$, in which case a sale is always guaranteed, or a high price, $p=b_{H}$, in which case a sale occurs with probability $\beta$ only.

The commission paid to the real estate agent is a fraction $\phi(0 \leq \phi \leq 1)$ of the selling price of the house, and is contingent on the sale of the house. The agent is not paid if there is no sale.

\footnotetext{
${ }^{3}$ As mentioned in the introduction, sellers in the United States generally pay 6 percent commission and rarely bargain with their brokers on lower rates. Thus, it makes sense to assume that the commission rate is exogenously given.
} 
The timing of the sale is as follows. In each period the seller, via a real estate broker, quotes a price to one potential buyer who is drawn from the above distribution. The buyer then accepts the offer, or rejects it, in which case the seller must quote a price to a newly drawn buyer in a subsequent period. Let $c_{s}$ and $c_{a}$ denote the seller's and agent's cost (value of time) of having to postpone the sale of the house by one period. The costs of delaying the transaction may include forgone interest income and property taxes. Clearly, a sale is guaranteed if the seller asks for a low price, $p=b_{L}$, in which case both types of buyers would (weakly or strongly) benefit from purchasing the house. However, if the seller asks for a high price, $p=b_{H}$, only one type agrees to buy the house, and this occurs with probability $\beta$.

To simplify the model, a time discount factor is not formally introduced into the model. Then, the seller's expected net gain from setting a high price, $p=b_{H}$, is

$$
\mathrm{E} \pi_{s}\left(p=b_{H}\right)=(1-\phi) b_{H}-\sum_{t=1}^{\infty}(1-\beta)^{t} c_{s}=(1-\phi) b_{H}-\frac{(1-\beta) c_{s}}{\beta}
$$

The first term in (1) is the price net of broker's commission. Note that with probability 1 the sale of the house must occur in some period $t$ because the probability of "drawing" a high-valuation buyer is strictly positive. The second term is the seller's expected cost of delay in selling the house. The cost of delay is generated by a sequence of events in which only low-valuation buyers appear during the first $t$ periods [probability $(1-\beta)^{t}$ ]. Each period when a low-valuation buyer is drawn, the buyer rejects the seller's price $p=b_{H}$, in which case the seller bears a delay cost of $c_{s}$. For example, a low-price buyer emerges in period $t=1$ with probability $1-\beta$; low-price buyers emerge in both periods $t=1,2$ with probability $(1-\beta)^{2}$, and so on. To illustrate some specific examples of the seller's expected cost of delay: if $\beta=1$ there is no cost of delay; whereas the opposite extreme $\beta \rightarrow 0$ generates an infinite cost of delay. If $\beta=0.5$, the expected cost of delay is exactly $c_{s}$; and $4 c_{s}$ if $\beta=0.2$.

The above discussion implies that the seller's expected gain (as a function of price) each time a new potential buyer appears is

$$
\mathrm{E} \pi_{s}= \begin{cases}(1-\phi) b_{L} & \text { if } p=b_{L} \\ (1-\phi) b_{H}-(1-\beta) c_{s} / \beta & \text { if } p=b_{H}\end{cases}
$$


In either case, the seller collects only a fraction $(1-\phi)$ of the price because a fraction $\phi$ is paid to the agent. The seller's expected profit (2) provides the condition under which the seller is better off asking for a low price rather than a high price, which is given by

$$
\mathrm{E} \pi_{s}\left(p=b_{L}\right) \geq \mathrm{E} \pi_{s}\left(p=b_{H}\right) \quad \text { iff } \quad \frac{(1-\beta) c_{s}}{\beta} \geq(1-\phi)\left(b_{H}-b_{L}\right)
$$

That is, if the cost of a one-period delay in the sale of the house, $c_{s}$, is sufficiently high, then the seller should set a low price, which would guarantee an immediate sale. Otherwise, the seller's expected gain is higher when the seller sets a high price, under which an immediate sale occurs with only probability $\beta$. Setting a low price is also profitable for the seller when the difference between the buyers' valuation, $b_{H}-b_{L}$, is low, because "waiting" for a high-valuation buyer to appear does not significantly increase the net-of-commission price.

Consider now the real estate agent's expected profit under low and high price offers made to a randomly selected buyer. Recalling that the agent collects a fee equals to a fraction $\phi$ of the sale price, the agent's expected profit is

$$
\mathrm{E} \pi_{a}= \begin{cases}\phi b_{L} & \text { if } p=b_{L} \\ \phi b_{H}-(1-\beta) c_{a} / \beta & \text { if } p=b_{H}\end{cases}
$$

The agent's expected profit (4) is the analog of the seller's expected profit (2). The only differences are the shares in the selling price and the cost of delay if $c_{s} \neq c_{a}$. The agent's expected profit (4) implies that

$$
\mathrm{E} \pi_{a}\left(p=b_{L}\right) \geq \mathrm{E} \pi_{a}\left(p=b_{H}\right) \quad \text { iff } \quad \frac{(1-\beta) c_{a}}{\beta} \geq \phi\left(b_{H}-b_{L}\right)
$$

Figure 1 illustrates the parameter range under which the seller and the broker agree and disagree on setting a low price, $p=b_{L}$. Figure 1 shows that if the seller and the buyer have the same cost of delaying a transaction $\left(c=c_{s}=c_{a}\right)$, the seller's and the agent's interests coincide only if the cost of delay takes extreme values. At intermediate values of the cost of delay, the seller's and the agent's interests diverge. Figure 1 implies the following set of results.

Result 1. Suppose the agent's commission rate is below 50 percent $(\phi<0.5)$. Then, 


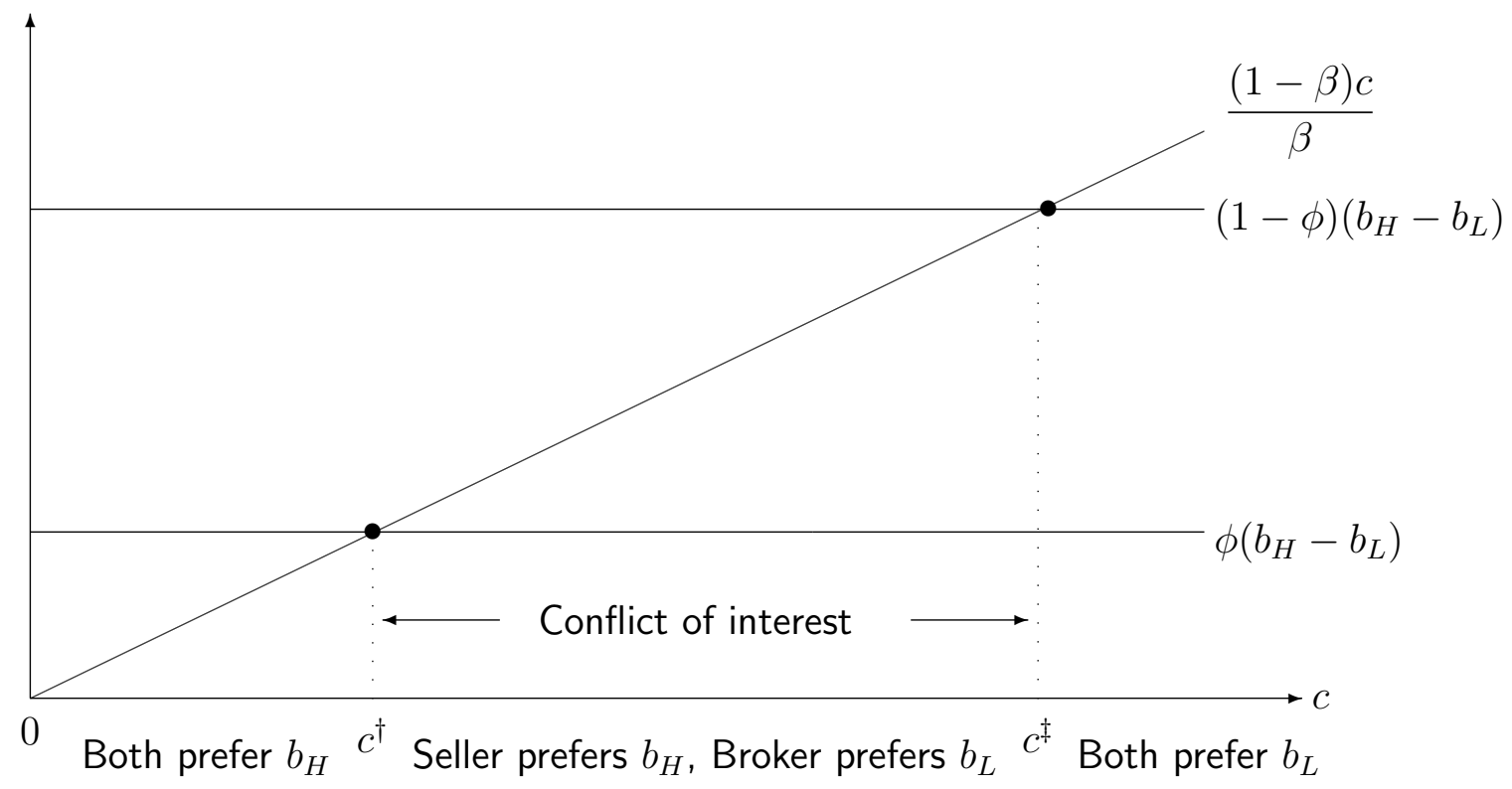

Figure 1: Conflict of interest between a seller and a broker as a function of costs of delay: Comparing conditions (3) and (5). Note: Figure assumes equal cost of delay, $c=c_{s}=c_{a}$, and $\phi<0.5$.

(a) If the cost of delay is high, $c_{s}=c_{a}>c^{\ddagger}$, both the seller and the agent would choose to set a low price, $p=b_{L}$.

(b) If the cost of delay is low, $c_{s}=c_{a}<c^{\dagger}$, both the seller and the agent would choose to set a high price, $p=b_{H}$.

(c) Otherwise, the seller would choose a high price, whereas the agent would recommend setting a low price.

(d) There does not exist a situation in which the seller sets a low price while the agent recommends setting a high price.

Result 1 shows that a real estate agent has an incentive to "convince" the seller to lower the price below the level that would be profitable for the seller. This happens because, compared with the seller, the agent has less to gain from selling at a high price.

Observe that Result 1 relies on the assumption that the agent receives less than 50 percent commission $(\phi<0.5)$. This assumption is obviously realistic, considering the fact that real estate agents in the United States earn no more than 6 percent commission. In some other countries, 
the standard commission could range between 1.5 percent and 2 percent. Clearly, Results 1(c) and $1(\mathrm{~d})$ would be reversed under the unrealistic case in which $\phi>0.5$.

Finally, from a social welfare point of view, social loss occurs only if the sale of the house is delayed, in which case the seller and the agent bear the per-period $\operatorname{costs} c_{s}$ and $c_{a}$, respectively. Clearly, the sale price does not have any effect on social welfare because it is merely a transfer from the buyer to the seller, and the commission is a transfer from the seller to the broker. In order to compute the expected social loss from setting a high price, we first compute the expected number of periods it takes to sell the house, denoted by $\mathrm{E} T$, when the price is set to $p=b_{H}$. Appendix A shows that

$$
\mathrm{E} T=\beta \cdot 1+(1-\beta) \beta \cdot 2+(1-\beta)^{2} \beta \cdot 3+\cdots=\beta \sum_{t=1}^{\infty}\left[(1-\beta)^{t-1} \cdot t\right]=\frac{1}{\beta}
$$

For example, if there are equal numbers of low-valuation and high-valuation buyers $(\beta=0.5)$, then the house is expected to be sold within $\mathrm{E} T=2$ periods. If $\beta=1 / 3$, the house is expected to be sold in three periods, and so on. It can be concluded from (6) that the expected social loss from setting a high price is $\left(c_{s}+c_{a}\right) / \beta$. Setting a low price would eliminate this loss because a low price generates an immediate sale. Thus, despite the fact that real estate agents may not work for the best interest of sellers, they generate faster sales, and this lowers or eliminates sellers' and buyers' costs of delay in selling the house.

\section{Seller-determined Price with Exogenously Given Com- mission Rate: Multiple Buyer Types}

This section extends the model from two types of potential buyers to a continuum of buyers whose maximum willingness to pay is uniformly distributed on the interval $\left[b_{L}, b_{H}\right]$, where $b_{H}>b_{L} \geq 0$. In this environment, a buyer with valuation $b \in\left[b_{L}, b_{H}\right]$ accepts all price offers $p \leq b$ (and buys the house), and rejects all price offers $p>b$. Therefore, for any price $p \geq 0$ set by the seller, the 
probability that a sale is made in one period (with no delay) is

$$
\beta(p)= \begin{cases}0 & \text { if } p>b_{H} \\ \frac{b_{H}-p}{b_{H}-b_{L}} & \text { if } b_{L} \leq p \leq b_{H} \\ 1 & \text { if } p<b_{L} .\end{cases}
$$

The following assumption is needed to obtain interior solutions.

Assumption 1. Costs of delay in selling the house are bounded relative to the range of buyers' willingness to pay. Formally, $c_{s}<\phi\left(b_{H}-b_{L}\right)$ and $c_{a}<(1-\phi)\left(b_{H}-b_{L}\right)$.

Clearly, if Assumption 1 is reversed, high costs of delay may induce the seller or the broker to reduce the price to a level that secures an immediate sale with 100 percent probability. Assumption 1 can also be expressed as a lower bound on the range of the buyers' distribution, $b_{H}-b_{L}$.

Using the same method of constructing the seller's objective function (1) and using (7), the seller sets a price $p_{s}$ to maximize expected gain defined by

$$
\begin{aligned}
\max _{b_{L} \leq p \leq b_{H}} \mathrm{E} \pi_{s}(p)=(1-\phi) p-\sum_{t=1}^{\infty}[1 & -\beta(p)]^{t} c_{s} \\
& =(1-\phi) p-\frac{[1-\beta(p)] c_{s}}{\beta(p)}=(1-\phi) p-\frac{\left(p-b_{L}\right) c_{s}}{b_{H}-p}
\end{aligned}
$$

The first term in (8) is the price net of the commission paid to the broker. Note that with probability 1 the house must sell in some finite period $t$. The second term of (8) is the seller's expected cost associated with the delay in selling the house.

Solving (8) yields a selling price and the corresponding probability of an immediate sale

$$
p_{s}=b_{H}-\sqrt{\frac{\left(b_{H}-b_{L}\right) c_{s}}{1-\phi}} \text { and } \beta\left(p_{s}\right)=\sqrt{\frac{c_{s}}{(1-\phi)\left(b_{H}-b_{L}\right)}} .
$$

Thus, the price that maximizes the seller's profit decreases with the broker's commission $\phi$ and with the cost of delay $c_{s}$. Consequently, an increase in the commission rate $\phi$ increases the probability of an immediate sale $\beta(p)$. Note that Assumption 1 guarantees that the equilibrium probability of an immediate sale satisfies $\beta<1$. 
Suppose now that the agent (instead of the seller) determines the price. Then, the agent sets the price $p_{a}$ to solve

$$
\max _{b_{L} \leq p \leq b_{H}} \mathrm{E} \pi_{a}(p)=\phi p-\sum_{t=1}^{\infty}[1-\beta(p)]^{t} c_{a}=\phi p-\frac{[1-\beta(p)] c_{a}}{\beta(p)}=\phi p-\frac{\left(p-b_{L}\right) c_{a}}{b_{H}-p} .
$$

The first term in (10) is the commission paid to the broker from selling the house. The second term is the broker's expected cost associated with the delay in selling the house. Solving (10) yields

$$
p_{a}=b_{H}-\sqrt{\frac{\left(b_{H}-b_{L}\right) c_{a}}{\phi}} \text { and } \beta\left(p_{a}\right)=\sqrt{\frac{c_{a}}{\phi\left(b_{H}-b_{L}\right)}} .
$$

Thus, a higher commission $\phi$ paid to the broker increases the broker's profit-maximizing price and reduces the probability of an immediate sale. This result will become important in Section 4, which assumes that the seller delegates the price decision to the broker (or is heavily influenced by the broker's opinion regarding the selling price).

Comparing (9) with (11) yields the following set of results.

Result 2. Suppose the seller and the agent have equal costs of delay, $c_{s}=c_{a}=c$. Then,

(a) The agent's profit-maximizing price is lower than the seller's value-maximizing price if and only if the agent earns less than 50 percent commission. Formally, $p_{a} \leq p_{s}$ if and only if $\phi \leq 0.5$.

(b) The difference between the two prices becomes larger as the commission rate declines. Formally, $d\left(p_{s}-p_{a}\right) / d \phi<0$.

(c) The house is expected to be sold faster under the agent's price relative to the seller's price. Formally, $\beta\left(p_{a}\right)>\beta\left(p_{s}\right)$.

Result 2(c) explains why the broker-determined price is lower than the seller-determined pricebecause the broker has more to gain than the seller from a faster sale. 


\section{Seller Determines the Commission and Broker Deter- mines the Price}

So far, our analysis was based on the assumption that the seller must pay a predetermined commission rate, $\phi$, which cannot be negotiated. This assumption was fairly realistic in view of our earlier discussion concerning the FTC investigation of the widely used (basically uniform across all real estate agencies) commission rate of $\phi=0.06$ in the United States.

This section takes the opposite approach by letting the seller determine the commission rate paid to a real estate broker. Clearly, this rate would be close to zero if we were assuming that the seller also determines the price of the house. To avoid this problem, this section assumes that the seller lets the agent determine the price, see Footnote 1. This assumption provides the seller with the incentive to pay some commission to the broker in order to motivate the broker to raise the price, which would consequently prolong the expected time needed to sell the house.

Consider the following two-stage game between a seller of a house and a broker hired to sell the house. In the first stage, the seller offers the broker a commission rate of $\phi(0<\phi<1)$ as a fraction of the price. In the second stage, the broker takes the commission rate $\phi$ as given and chooses the price of the house to maximize (10). The broker's decision rule is a price as a function of commission $p(\phi)$. In the first stage, the seller can use this decision rule to determine the broker's commission $\phi$ to maximize the expected net-of-commission gain defined by (8).

The solution to the second stage is already given in (11). Substituting (11) for both $p$ and $\beta$ into the seller's objective function (8), in the first stage the seller sets the commission rate $\phi$ to solve

$$
\max _{\phi} \pi_{s}(\phi)=(1-\phi) p-\frac{[1-\beta(p)] c_{s}}{\beta(p)}=(1-\phi) b_{H}+c_{S}-\frac{\sqrt{b_{H}-b_{L}}\left[\phi c_{s}+(1-\phi) c_{a}\right]}{\sqrt{\phi c_{a}}} .
$$

Note that the seller's profit function (12) is strictly concave with respect to $\phi$ because

$$
\pi_{s}^{\prime \prime}(\phi)=\frac{\sqrt{b_{H}-b_{L}}\left[c_{s} \phi-c_{a}(\phi+3)\right]}{4 \sqrt{\phi^{5} c_{a}}}<0 \text { if } c_{s}<\frac{\phi+3}{\phi} c_{a},
$$

which provides a sufficiently wide range of cost parameters under which the calibrations in Section 5 are conducted. In particular, it holds when the seller and broker have equal costs of delay, 
$c_{s}=c_{a}$

The first-order condition of (12) for the general case of unequal costs of delay is

$$
0=\pi_{s}^{\prime}(\phi)=\frac{\sqrt{b_{H}-b_{L}}\left[c_{a}(\phi+1)-c_{s} \phi\right]}{2 \sqrt{\phi^{3} c_{a}}}-b_{H},
$$

which provides the key relationship needed for the calibration of the seller-determined broker's commission. It should be noted that for the specific case of equal costs of delay, $c_{s}=c_{a}=c$, the commission can be explicitly extracted from (13) to be

$$
\phi\left(c_{s}=c_{a}=c\right)=\sqrt[3]{\frac{c\left(b_{H}-b_{L}\right)}{\left(2 b_{H}\right)^{2}}} .
$$

Thus, for the special case of equal costs of delay, the broker's commission that maximizes the seller's expected gain increases (at a lower rate) with the cost of delay $c$. That is, a higher cost of delay will induce the broker to reduce the price in order to get a faster sale. The seller must then increase commission in order to provide the opposite incentive. Although the seller also bears a higher expected cost of delay, the seller has more to gain from a higher price than the broker.

\section{Calibrations the Seller-determined Commission Rate}

The model presented in Section 4 was constructed for purpose of calibrating the broker's commission rate $\phi$ that would maximize the seller's expected gain, knowing that the agent will attempt to sell the house at higher price when the commission is set at a higher rate according to (11). The implicitly determined commission rate chosen by the seller given in (13) requires knowledge of the cost of delay parameters $c_{s}$ and $c_{a}$, and the buyers' distribution parameters $b_{L}$ and $b_{H}$. Substituting these into (13), numerical methods can be used to extract the corresponding seller's most-preferred commission rate $\phi\left(c_{s}, c_{a}, b_{L}, b_{H}\right)$.

Table 1 exhibits median and average prices of houses in the United States in the years 2005 to 2008. In view of Table 1 , to determine the values of $b_{L}$ and $b_{H}, I$ assume that buyers' average willingness to pay for a private house is $\$ 250,000$. 


\begin{tabular}{r|rr} 
Year & Median & Average \\
\hline 2005 & $\$ 219,600$ & $\$ 266,600$ \\
2006 & $\$ 221,900$ & $\$ 268,200$ \\
2007 & $\$ 218,900$ & $\$ 265,800$ \\
\hline
\end{tabular}

Table 1: Seasonally adjusted median and average house prices in the United States, 2005-2007. Source: National Association of Realtors' Web site, www.realtors.org.

To cover a wide range of possibilities, the calibrations below are conducted under three extreme distributions around $\$ 250,000$, given by the buyers' willingness to pay intervals $\left[b_{L}, b_{H}\right]=$ $[\$ 240,000, \$ 260,000],[\$ 225,000, \$ 275,000]$, and $[\$ 200,000, \$ 300,000]$. These three distributions reflect standard deviations of $\$ 5,778, \$ 14,433$, and $\$ 28,867$, respectively, around a mean willingness to pay of $\$ 250,000$.

The three sections of Table 2 display the calibrated values of seller-determined broker's commission rate $\phi$ extracted from (13), the resulting price of a house as determined by the broker, and consequently the probability that the house will sell in one period, both given in (11). The

\begin{tabular}{r|rrrrr}
\hline \multicolumn{7}{c}{ Commission $\phi$} \\
$c_{s} \backslash c_{a}$ & 100 & 300 & 500 & 700 & 900 \\
\hline 100 & $1.95 \%$ & $2.85 \%$ & $3.39 \%$ & $3.81 \%$ & $4.50 \%$ \\
500 & $1.85 \%$ & $2.78 \%$ & $3.33 \%$ & $3.75 \%$ & $4.50 \%$ \\
1000 & $1.74 \%$ & $2.69 \%$ & $3.26 \%$ & $3.69 \%$ & $4.50 \%$ \\
1500 & $1.64 \%$ & $2.61 \%$ & $3.19 \%$ & $3.62 \%$ & $4.50 \%$ \\
\hline \multicolumn{5}{c}{ Price $p(\phi)$} \\
$c_{s} \backslash c_{a}$ & 100 & 300 & 500 & 700 & 900 \\
\hline 100 & $\$ 249,868$ & $\$ 245,479$ & $\$ 242,829$ & $\$ 240,825$ & $\$ 240,000$ \\
500 & $\$ 249,605$ & $\$ 245,296$ & $\$ 242,675$ & $\$ 240,688$ & $\$ 240,000$ \\
1000 & $\$ 249,277$ & $\$ 245,068$ & $\$ 242,483$ & $\$ 240,516$ & $\$ 240,000$ \\
1500 & $\$ 248,950$ & $\$ 244,840$ & $\$ 242,290$ & $\$ 240,344$ & $\$ 240,000$ \\
\hline \multicolumn{5}{|c}{ Sale Probability $\beta(p)$} \\
$c_{s} \backslash c_{a}$ & 100 & 300 & 500 & 700 & 900 \\
\hline 100 & 0.51 & 0.73 & 0.86 & 0.96 & 1.00 \\
500 & 0.52 & 0.74 & 0.87 & 0.97 & 1.00 \\
1000 & 0.54 & 0.75 & 0.88 & 0.97 & 1.00 \\
1500 & 0.55 & 0.76 & 0.89 & 0.98 & 1.00 \\
\hline
\end{tabular}

Table 2: Seller-determined broker's commission, broker-determined price, and sale probability, assuming that buyers are distributed on $[\$ 240,000, \$ 260,000]$. 
calibrations in Table 2 are based on the seller's cost of delay $c_{s}$, ranging from $\$ 100$ to $\$ 1500$ where a period is taken to be one month. To convince the reader that this range is sufficient to cover all types of sellers, consider the following exercise. If a house is sold and the proceeds are invested in a saving account bearing a 5 percent annual interest rate, the monthly loss of income from each one-month delay in selling the house is $0.05 \cdot \$ 250,000 / 12 \approx \$ 1041$. The equivalent computation for a 4 percent interest rate yields a forgone income of $\$ 833$. Clearly, a delay in selling a house generates some additional costs, such as maintenance and property tax. In view of this discussion, the choice of seller's monthly cost of delay ranging from $\$ 100$ to $\$ 1500$ is sufficient to cover a wide variety of sellers. Since brokers do not bear a significant forgone interest income associated with a delay, brokers' cost of delay should be lower than that of sellers, and hence a range between $\$ 100$ to $\$ 900$ should be sufficient to cover most types of brokers.

Table 2 (and similarly Tables 3 and 4 below) reveals the following results concerning the seller-determined broker's commission.

Result 3. Suppose the broker's commission $\phi$ is determined by the seller so as to maximize the seller's expected net-of-commission gain from selling a house. Also, suppose that the seller delegates the selling price decision to the broker. Then,

(a) The commission increases with the broker's cost of one period delay, $c_{a}$.

(b) The commission declines with the seller's cost of one period delay, $c_{s}$.

Result 3(a) shows that an increase in the broker's cost of delay induces the seller to increase the commission in an attempt to prevent the broker from setting a very low price. Clearly, with larger cost of delay, the broker has an incentive to reduce the price in order to increase the probably of an immediate sale, $\beta$. The second and third sections of Table 2 reveal that despite the increase in commission, the broker reduces the price (when $c_{a}$ increases), which in turn increases the probability of an immediate sale. This means that it is not profitable for the seller to increase the commission to induce the broker to maintain the same price when the broker's cost of delay increases. Instead, the seller increases commission only to mitigate the fall in price but not to totally prevent it. The right-most column of Table 2 displays a corner solution associated with 
the broker's high cost of delay, $c_{a}=\$ 900$ (and above). In this case, the seller cannot prevent the agent from setting the price to the lowest level on the buyers' distribution, $p=\$ 240,000$, thereby guaranteeing an immediate sale with probability $\beta=1$. This result is special in the sense that it relies on a relatively narrow range of buyers' willingness to pay (in contrast to Tables 3 and 4 which calibrate for a wider range of buyers' distribution).

Scrolling down on each column of Table 2 reveals that the commission set by the seller is not very sensitive to the seller's cost of delay (as opposed to changes in the broker's cost of delay discussed earlier). For example, the column under the 100 shows that when the seller's cost of one period delay jumps from $\$ 100$ to $\$ 1500$, the seller lowers the broker's commission by very small percentage points (1.95 percent to 1.64 percent). The reason for this small reduction is that an increase in the seller's cost of delay increases the seller's benefit from an immediate sale; this is accomplished by slightly reducing the broker's commission $\phi$ thereby inducing the broker to lower the price $p(\phi)$, in order to increase the probability of an immediate sale $\beta(p)$.

\begin{tabular}{r|rrrrr}
\hline \multicolumn{5}{c}{ Commission $\phi$} \\
$c_{s} \backslash c_{a}$ & 100 & 300 & 500 & 700 & 900 \\
\hline 100 & $2.55 \%$ & $3.73 \%$ & $4.46 \%$ & $5.01 \%$ & $5.47 \%$ \\
500 & $2.83 \%$ & $3.61 \%$ & $4.36 \%$ & $4.92 \%$ & $5.38 \%$ \\
1000 & $2.20 \%$ & $3.47 \%$ & $4.23 \%$ & $4.81 \%$ & $5.28 \%$ \\
1500 & $2.04 \%$ & $3.21 \%$ & $4.11 \%$ & $4.70 \%$ & $5.18 \%$ \\
\hline \multicolumn{5}{|c}{ Price $p(\phi)$} \\
$c_{s} \backslash c_{a}$ & 100 & 300 & 500 & 700 & 900 \\
\hline 100 & $\$ 260,990$ & $\$ 254,959$ & $\$ 251,321$ & $\$ 248,573$ & $\$ 246,315$ \\
500 & $\$ 260,514$ & $\$ 254,629$ & $\$ 251,043$ & $\$ 248,324$ & $\$ 246,086$ \\
1000 & $\$ 259,921$ & $\$ 254,217$ & $\$ 250,695$ & $\$ 248,013$ & $\$ 245,800$ \\
1500 & $\$ 259,931$ & $\$ 253,805$ & $\$ 250,347$ & $\$ 247,702$ & $\$ 245,514$ \\
\hline & 100 & Sale Probability $\beta(p)$ & & \\
$c_{s} \backslash c_{a}$ & 300 & 500 & 700 & 900 \\
\hline 100 & 0.28 & 0.40 & 0.47 & 0.53 & 0.57 \\
500 & 0.29 & 0.41 & 0.48 & 0.53 & 0.58 \\
1000 & 0.30 & 0.42 & 0.49 & 0.54 & 0.58 \\
1500 & 0.31 & 0.42 & 0.49 & 0.55 & 0.59 \\
\hline
\end{tabular}

Table 3: Seller-determined broker's commission, broker-determined price, and sale probability, assuming that buyers are distributed on $[\$ 225,000, \$ 275,000]$. 


\begin{tabular}{r|rrrrr}
\hline \multicolumn{5}{c}{ Commission $\phi$} \\
$c_{s} \backslash c_{a}$ & 100 & 300 & 500 & 700 & 900 \\
\hline 100 & $3.03 \%$ & $4.45 \%$ & $5.32 \%$ & $5.99 \%$ & $6.54 \%$ \\
500 & $2.80 \%$ & $4.28 \%$ & $5.18 \%$ & $5.86 \%$ & $6.42 \%$ \\
1000 & $2.55 \%$ & $4.09 \%$ & $5.00 \%$ & $5.70 \%$ & $6.27 \%$ \\
1500 & $2.33 \%$ & $3.90 \%$ & $4.84 \%$ & $5.55 \%$ & $6.13 \%$ \\
\hline \multicolumn{5}{|c}{ Price $p(\phi)$} \\
$c_{s} \backslash c_{a}$ & 100 & 300 & 500 & 700 & 900 \\
\hline 100 & $\$ 281,829$ & $\$ 274,047$ & $\$ 269,357$ & $\$ 265,815$ & $\$ 262,908$ \\
500 & $\$ 281,095$ & $\$ 273,538$ & $\$ 268,928$ & $\$ 265,432$ & $\$ 262,555$ \\
1000 & $\$ 280,182$ & $\$ 272,903$ & $\$ 268,391$ & $\$ 264,952$ & $\$ 262,114$ \\
1500 & $\$ 279,275$ & $\$ 271,268$ & $\$ 267,855$ & $\$ 263,994$ & $\$ 261,673$ \\
\hline & 100 & Sale Probability $\beta(p)$ & & \\
$c_{s} \backslash c_{a}$ & 300 & 500 & 700 & 900 \\
\hline 100 & 0.18 & 0.26 & 0.31 & 0.34 & 0.37 \\
500 & 0.19 & 0.26 & 0.31 & 0.35 & 0.37 \\
1000 & 0.20 & 0.27 & 0.32 & 0.35 & 0.38 \\
1500 & 0.21 & 0.28 & 0.32 & 0.36 & 0.38 \\
\hline
\end{tabular}

Table 4: Seller-determined broker's commission, broker-determined price, and sale probability, assuming that buyers are distributed on $[\$ 200,000, \$ 300,000]$.

Tables 3 and 4 present calibrations for wider mean-preserving-spread distributions of buyers' willingness to pay, $[\$ 225,000, \$ 275,000]$ and $[\$ 200,000, \$ 300,000]$, respectively. Comparing the three tables reveals how the seller-determined commission paid to a broker is affected by enlarging the range of buyers' willingness to pay around the same mean price $\$ 250,000$.

Result 4. An increase in the range of buyers' willingness to pay around a fixed mean will

(a) increase the seller-determined commission rate, $\phi$, and therefore

(b) increase the broker-determined (or broker-influenced) price of the house, and hence,

(c) decrease the probability of an immediate sale.

In fact, comparing Table 2 with Tables 3 and 4 reveals that the broker sets a price below the mean willingness to pay when the range is narrow (Table 2), whereas the broker sets prices above the mean under wider distributions of buyers' willingness (Tables 3 and 4).

Table 5 confirms Result 4 by displaying the values from Tables 2, 3, and 4 for "representative" 
costs of delay, $c_{s}=\$ 1000$ and $c_{a}=\$ 300$. The column under the " $\phi$ " in Table 5 confirms

\begin{tabular}{l|ccc} 
Buyer Distribution & $\phi$ & $p(\phi)$ & $\beta(\phi)$ \\
\hline$[\$ 240,000, \$ 260,000]$ & $2.69 \%$ & $\$ 245,296$ & 0.75 \\
{$[\$ 225,000, \$ 275,000]$} & $3.47 \%$ & $\$ 254,217$ & 0.42 \\
{$[\$ 200,000, \$ 300,000]$} & $4.09 \%$ & $\$ 272,903$ & 0.27 \\
\hline
\end{tabular}

Table 5: The effect of widening the distribution of willingness to pay on seller-determined commission paid to real estate brokers.

Result 4(a) showing that a wider distribution increases the commission sellers choose to pay their real estate agents. This happens because a wider distribution increases the seller's expected gain from selecting a higher price, as predicted by Result 4(b) and confirmed on the " $p$ " column in Table 5. A higher price above the mean prolongs the sale of the house, as predicted by Result 4(c) and confirmed on the " $\beta$ " column in Table 5.

\section{Discussion}

The conflict of interest between a seller of a house and a real estate agent hired by the seller harms the seller and benefits the buyer. In this model, real estate agents improve social welfare because they reduce the cost of delay of selling houses. That is, the "pressure" agents put on sellers to reduce their prices shortens the amount of time it takes to sell a house. Since social welfare is not affected by the allocation of rents between sellers and buyers, and between sellers and real estate brokers, social welfare is enhanced when sales decisions are delegated to realtors.

The conflict of interest identified in this paper prevails not only in the market for real estate, but also in some other markets. For example, in court cases in which attorneys receive a fraction of the final settlement instead of fixed fees, attorneys may recommend their clients to settle on lower compensation levels than the level that would maximize the expected benefit of the clients. Similar conflicts may exist between stock brokers and their clients because brokers' compensation is contingent on their clients' actual purchase and sale of stocks and mutual funds, and even in agricultural contracts involving cropsharings. 
The calibration results hint that the ongoing commission rate of 6 percent exceeds sellers' value-maximizing rate even in the extreme situation in which the price of the house is decided by the broker (in which case a higher commission induces the broker to raise price and prolong the expected time needed for selling the house). However, it should be pointed out that this interpretation relies on the assumption that only one agent receives the full commission for selling the house. If several brokers split the commission (such as the buyer's and seller's brokers, and the agencies that employ these realtors) a 6 percent commission may be needed to motivate the broker to sell at a high price. The model developed in this paper and the calibration itself can be easily modified to capture situations in which several brokers or agencies split the commission paid by house sellers. The important empirical question to ask in this context is what fraction of real estate transactions involve one, two, three, or four real estate brokers.

Another related empirical question is how the levels of commission affect the speed of home sales. This investigation may (or may not) be accomplished by comparing the number of house visits of potential buyers divided by the number of brokers involved in the sale. One could also investigate whether houses sold in countries with lower commission rates sell faster than in the United States. Clearly, in such investigations it may be impossible to control for the institutional differences of housing markets in different countries.

Two features are missing from the present simple formulation: First, the model does not embed any benefits for the seller in hiring a real estate broker. The introduction discusses these possible benefits. To incorporate this feature, the sellers' utility function should be modified slightly to include the additional possible sellers' gains from employing a broker relative to selling "by owner" only. Second, this model does not analyze how the level of commission influences the efforts exerted by brokers, and how these efforts are translated into the speed of sale. It is not clear whether any of these proposed extensions would prolong or shorten the length of time it would take to sell a house, and for this reason I chose to ignore these two effects and to keep the model and the calibrations as simple as possible. But it should be noted that a percentage commission (as opposed to a lump-sum fee) generates an incentive for brokers to exert more effort on selling more expensive houses than on low-value houses. 


\section{Appendix A. Proof of Equation (6)}

The right side of (6) can be written as

$$
\begin{aligned}
\beta\left\{\left[1+(1-\beta)+(1-\beta)^{2}\right.\right. & +\cdots]+\left[(1-\beta)+(1-\beta)^{2}+\cdots\right] \\
& \left.+\left[(1-\beta)^{2}+(1-\beta)^{3}+\cdots\right]+\left[(1-\beta)^{3}+(1-\beta)^{4}+\cdots\right]\right\} .
\end{aligned}
$$

Since each bracket term constitutes a converging sequence, the above equals to

$$
\beta\left\{\frac{1}{1-(1-\beta)}+\frac{1-\beta}{1-(1-\beta)}+\frac{(1-\beta)^{2}}{1-(1-\beta)}+\cdots\right\}=\sum_{t=0}^{\infty}(1-\beta)^{t}=\frac{1}{\beta} \text {. }
$$

\section{References}

Biglaiser, G. 1993. "Middlemen as Experts." RAND Journal of Economics 24: 212-223.

Biglaiser, G. and J. Friedman. 1994. "Middlemen as Guarantors of Quality." International Journal of Industrial Organization 12: 509-31.

Carroll, W. 1989. "Fixed-Percentage Commissions and Moral Hazard in Residential Real Estate Brokerage." Journal of Real Estate Finance \& Economics 2: 349-365.

Federal Trade Commission and U.S. Department of Justice. 2007. "Competition in the Real Estate Brokerage Industry." Washington D.C.

Garella, P. 1989. "Adverse Selection and the Middleman." Economica 56: 395-400.

Hackett, S. 1992. "A Comparative Analysis of Merchant and Broker Intermediation." Journal of Economic Behavior \& Organization 18: 299-315.

Hackett, S. 1993. "Consignment Contracting." Journal of Economic Behavior \& Organization 20: 247-53.

Knoll, M. 1988. "Uncertainty, Efficiency, and the Brokerage Industry." Journal of Law \& Economics 31: 249-263.

Levitt, S., and S. Dubner. 2005. Freakonomics. New York: William Morrow.

Levitt, S., and C. Syverson. 2005. "Market Distortions When Agents Are Better Informed: The Value of Information in Real Estate." NBER Working Paper No. 11053. 
Merlo, A., F. Ortalo-magné, and J. Rust. 2008. "The Home Selling Problem: Theory and Evidence." University of Maryland Working Paper.

Rubinstein, A., and A. Wolinksy. 1987. "Middlemen." Quarterly Journal of Economics 102: 581-594.

Salant, S. 1991. "For Sale by Owner: When to Use a Broker and How to Price a House." Journal of Real Estate Finance \& Economics 4: 157-173.

Schroeter, J. 1987. "Competition and Value-of-Service Pricing in the Residential Real Estate Brokerage Market." Quarterly Review of Economics \& Business 27: 29-40.

Yavaș, A. 1994. "Middlemen in Bilateral Search Markets." Journal of Labor Economics 12: 406-429.

Zorn, T., and J. Larsen. 1986. "The Incentive Effects of Flat-Fee and Percentage Commissions for Real Estate Brokers." Journal of the American Real Estate \& Urban Economics Association 14: 24-47. 